\section{Libertad y saber en el discurso pedagógico moderno. Elementos de análisis crítico de un discurso hegemónico}

\author{
Freedom and Knowledge in \\ Modern Pedagogical Discourse. \\ Elements for a Critical Analysis \\ of a Hegemonic Discourse
}

\author{
Liberdade e saber no discurso \\ pedagógico moderno. Elementos \\ para uma análise crítica do \\ discurso hegemônico
}

Armando Zambrano Leal*

\section{Resumen}

La pedagogía, hija de la ilustración, encontró en la libertad y en la autonomía su derrotero y su camino de positivización. Estos dos conceptos fueron el fundamento que orientó los fines del discurso pedagógico moderno y con ellos, la pedagogía, entendida como reflexión acerca del acto de educar, edificó una discursividad que se orientó por un ideal de naturaleza humana. La libertad se constituyó así en el eje de su autodeterminación, mientras que el aprendizaje se convirtió en el camino de la autonomía.

\section{Palabras clave}

modernidad; libertad; autonomía; relación con el saber; pedagogía; educación

\section{Abstract}

A child of Enlightenment, pedagogy finds in both freedom and autonomy its course, and its path to positivization. These two concepts were the grounds for the goals of modern pedagogical discourse. Along with them pedagogy, as a reflection on the act of educating, builds up a new discourse centered on an ideal of human nature. Thus, freedom became the core of self-determination, while learning became the way to autonomy.

\section{Key words}

modernity; freedom; autonomy; connection with knowledge; pedagogy; education

\section{Resumo}

A pedagogia, filha do Iluminismo, encontrou na liberdade e na autonomia, sua bússola e seu caminho de positivação. Estes dois conceitos foram a base sobre a qual sustentaram-se os fins do discurso pedagógico moderno e, com eles, a pedagogia, entendida como uma reflexão sobre o ato de educar, construiu seu discurso perspectivado por um ideal de natureza humana. A liberdade, portanto, tornou-se o eixo da sua autodeterminação, enquanto que a aprendizagem tornou-se o caminho da autonomia.

\section{Palavras chave}

modernidade; liberdade; autonomia; relação com o saber; pedagogia; educação

Fecha de recepción: Octubre 14 de 2015

Fecha de aprobación: Noviembre 18 de 2015 


\section{Introducción}

$\mathrm{L}$ a pedagogía moderna, que nace en los albores del siglo XVIII y se perfecciona a finales del siglo XIX, es heredera del pensamiento ilustrado. Es moderna porque integra su par semántico de progreso, innovación, experiencia y porque está fuertemente arraigada en la razón. Lo moderno es la antítesis de lo viejo, de la quietud, del régimen de verdad que instauró el dogma. Lo moderno es razón y juicio, únicos elementos del progreso. Lo moderno es sustancia en la naturaleza y esta es movimiento. Lo moderno es significación y sentido, elementos dirigidos a explicar la representación, y para algunos recibe el nombre de autorreflexividad (Jamenson, 2004). La pedagogía moderna es el movimiento de la naturaleza humana, que hace emerger la libertad en ella. La modernidad pedagógica es nombrada así por la autorreferencialidad, por el Yo del sujeto, por su significación en el mundo. La pedagogía moderna es el dispositivo que permite transmitir los elementos de saber para que el individuo moderno sea capaz de ser libre y ser autónomo, lo que significa ser capaz de hacer una autorreflexión y de encontrar sentido en lo que emprende como experiencia en el mundo.

La modernidad pedagógica encuentra sus raíces en la Ilustración, especialmente en los conceptos de libertad y de autonomía (Hamelin, 1999; Meirieu, 1998) y en esto sigue los preceptos del filósofo de Könisberg por cuanto la libertad se define como la capacidad que tiene todo individuo de servirse de su propio entendimiento (Kant, 1983). Ricoeur (1990) nos dice que Sapere aude expresa el acto de la razón, el entendimiento y las facultades del juicio en el orden de la razón práctica y de la razón crítica. La Ilustración pone al individuo y la sociedad en el centro de las acciones; marca la separación entre el mito y la superstición (Gadamer, 1997, p. 14). La razón vuelve autónomo y libre al ser humano.

La modernidad pedagógica apunta a la libertad del ser humano, este es su fin y para ello "elabora un proyecto colectivo que permite una cohesión del grupo en función de la orientación de la sociedad y, en consecuencia, de la educación y por esto mismo ella es en esencia libertad" (Houssaye, 1992, p.85). A partir de la razón, elemento discursivo fuerte de la modernidad pedagógica, la educación busca apartar a las personas de la superstición. La autonomía como saber instituido (Castoriadis, 2002, p. 167) nutre la libertad instituida e instituyente. Lograr que una persona sea autónoma es instituir la libertad, y esta es instituyente como principio pedagógico. El discurso instituido de la libertad es la base del saber pedagógico y legitima sus prácticas pues para educar se requiere de saberes. Estos se definen por la libertad instituyente: aprender para ser libres. El discurso pedagógico en la modernidad se rige por estos dos principios. El hombre es libre si aprende a servirse de su propio entendimiento; es autónomo en el ejercicio de la libertad pública. El saber libera y forja la autonomía en las personas; una persona es libre si es autónoma. La una y la otra afloran en el pensamiento crítico más contemporáneo. Saber reflexionar, saber comprender, saber argumentar es poseer el pensamiento autónomo. La palabra libre muestra el nivel de autonomía de un sujeto. Toda pedagogía que se reclame como moderna anticipa esto y se apoya en los saberes. Todo saber es liberador si logra promover en el individuo un aprendizaje autónomo y si anticipa un pensamiento crítico. Pero si bien la libertad aparece en el horizonte de realización de la pedagogía moderna, no es descabellado pensar que ella la encierra, que encierra su más puro ideal: el de la educación del ser humano. Y qué decir de la autonomía, concepto-dispositivo de realización de formas de ser, pensar, sentir.

\section{Libertad y aporía pedagógica}

En efecto, la cuestión de la libertad es objeto de todas las pedagogías que nacen del ideario moderno y que se adjetivan como diferenciada, experimental, activa, críticas, institucional, etc. Hijas de la modernidad, todas ellas postularían la libertad del niño. Según Avanzini (1998), esta idea muestra una paradoja educativa sobre la base de tres problemas. Primero,

... la intención educativa procede indudablemente de la ayuda al niño; ella es la supervivencia del ser humano. La dependencia inicial del ser humano lo subordina a la contingencia del proyecto educativo del cual él es objeto y proviene del planteamiento filosófico al identificar el sentido y al inferir su orientación. (p. 193-194).

Segundo,

... el proyecto educativo no tiene esperanza sino en relación con la maleabilidad, la plasticidad, la modificabilidad del sujeto; en definitiva de su educabilidad. El postulado de esta última es ante todo una exigencia lógica sin la cual sólo habría una especie de guardería o centro de detención; este postulado se articula a la voluntad de educar. (p. 194-195)

\section{Tercero,}

... la educación es un exigencia -no necesariamente una violencia- no porque el educador use la fuerza física o el chantaje afectivo sino también, mucho 
más radical y necesario, por el sólo hecho de que es él quien negocia al adoptar las normas que orientan su práctica [...] esta exigencia, como mejor lo señala Kant, apunta a una libertad [...] (p. 196)

Traducida como acto educativo, supone el acogimiento del niño, del otro, de un ser. Este acto impone la transmisión de valores, saberes y conocimientos. La acción ejercida por el adulto sobre el niño fija la originalidad de la práctica educativa, sin la cual la supervivencia de la especie humana no sería ni posible ni viable. Para la modernidad pedagógica, la relación adulto-niño es obligada y diferenciada. Obligada, pues es absurdo abandonar al niño y todo abandono es el fracaso de la educación y la penalidad egoísta del adulto. No hay educación en el abandono, pues educar es acoger y liberar. Cada niño es una naturaleza, a la vez, universal y particular. Él expresa una personalidad, reclama una atención especial. Su educación exige responsabilidad social e individual (Korczak, 1979, p. 88). Para la institución escolar, educar significa promover una responsabilidad colectiva; allí se funda su valor político. A la familia le corresponde el acogimiento y la preparación para la vida; ella delimita la dimensión privada de la educación.

La libertad es la base de la acción educativa moderna y define las prácticas que se consideran necesarias para el pleno desarrollo de la humanidad. Ella cierra el círculo de la naturaleza humana (nacer, crecer, morir) a través de procedimientos, métodos y objetos de saber. La libertad en educación se rige por modelos pedagógicos que guían la actividad institucional y docente. La pedagogía moderna postula como fundamental la libertad del sujeto y el modo de alcanzarla son los aprendizajes. En la modernidad, la discursividad pedagógica se nutre de la libertad. Por ejemplo, para la pedagogía nueva es a través del experimento como se forja la libertad de un sujeto. La experimentación de un gesto, una hipótesis, en las prácticas de ensayo y error, uno aprende "[...] educación y socialización van de la mano y están en el corazón del aprendizaje" (Best, 1996, pp. 14-15) pero solo hay socialización por medio de los saberes.

Para la modernidad pedagógica, el aprendizaje representa la práctica de la libertad y esto supone el saber. Haciendo, aplicando lo aprendido, es como el sujeto gana en libertad. Paradójicamente, aprender es una manera de controlar e incluso de suspender la libertad. De manera más precisa, aprender es la libertad en sí pero se suspende en la actividad, la acción y el resultado. Esta condición está fuertemente unida al concepto de transmisión y se desprende del siguiente principio:
... transmitir un saber es proponer información precisa, es dar explicaciones claras. No podemos presentar la posición que consiste en identificar la apropiación de un saber del estudiante según una única lógica; toda transmisión sigue una lógica y se apoya en teorías de referencia: empírico-asociacionistas, behavioristas sobre el condicionamiento operante y el refuerzo positivo cultural según el principio de interacción de la experiencia del sujeto.

(Mesnier, 1996, pp. 26-28)

Así mismo, la modernidad pedagógica postularía que la transmisión antecede al aprendizaje y suspende la libertad. Sólo cuando el sujeto se apropia, hace suyo un saber, irrumpe la libertad. Un hombre es libre en sus aprendizajes. La modernidad pedagógica agregaría que la libertad de un sujeto se logra mediante la práctica del saber (enseñar y aprender), pero nadie es libre sin aprendizaje y para aprender se requiere que otro enseñe. Los métodos y técnicas pedagógicas a través de la transmisión retienen al alumno y a la vez postulan su libertad. En este orden de ideas, para aprender se requiere suspender la libertad. La libertad pedagógica deviene un círculo aporético. Pero ¿por qué la práctica pedagógica es una aporía? La pedagogía frecuentemente se define como la reflexión sobre la práctica educativa pero tiene sus límites en los procedimientos; es un momento de libertad que jamás llega a universalizarse. Se rige por los métodos y con esto encierra la libertad. El método es el medio de control de la libertad o, si queremos, el método prepara para la libertad. Fiel a sus raíces modernas, la pedagogía moderna introduce el método como apoyo para la libertad y al hacerlo, la suspende.

No hay libertad sin resistencia, es la sentencia de la modernidad pedagógica. En efecto, la resistencia obliga al pedagogo a mirar de cerca su proyecto de educar, le exige venir sobre la libertad y está obligado a comprenderla en la resistencia del alumno. Insistentemente decimos que para forjar la libertad en el otro, la pedagogía construye dispositivos. Sin estos, el pedagogo sería incapaz de alcanzar sus objetivos y ninguna pedagogía podría construir un discurso de libertad. Precisamente, porque el dispositivo se encuentra en el corazón de la racionalidad pedagógica moderna es que la pedagogía encuentra su propia aporía. Mientras ella busca liberar, retiene; cuando enseña, limita. Mientras le enseño al niño, este resiste y al hacerlo accede a su libertad. No hay libertad fuera del aprendizaje y para que el niño aprenda fabrico dispositivos y lo encierro en mi deseo. Deseo de mi libertad en detrimento de la libertad del otro. En otros términos, enseñar es suspender la libertad del niño y a la vez forjarla. La resistencia es clave en el 
discurso filosófico de la pedagogía moderna pues sin ella la educación adviene instrucción o fabricación; la pedagogía postula el principio de libertad y a la vez es su prisionera.

\section{La autonomía como principio de regulación}

Si aceptamos que la ilustración libera al hombre de su culpable incapacidad de pensar por sí mismo (Kant, 2006, p. 25), la pedagogía se impone la dura tarea de organizar los saberes para que el sujeto acceda a la autonomía. Curiosamente, al mismo tiempo que vemos en el saber un medio de libertad, quedamos prisioneros de él. En esto reside la paradoja de la modernidad. Leyendo a Fichte, Philonenko encuentra que "la teoría del saber es en verdad una teoría de la libertad humana". La existencia del otro aparece claramente como un problema de reconocimiento, es un problema en sí.

En la medida en que la existencia del otro está vinculada con la idea de libertad, el otro no puede ser tratado como sujeto sino a condición de ser "reconocido" en su libertad; la intersubjetividad supone la limitación del conocimiento que fija su objeto como determinado. (Philonenko, 1999, p. 5)

Una idea de libertad según la tradición de la pedagogía moderna o de una modernidad pedagógica, tal como Soëtard lo ha propuesto, plantea un problema fundamental:

... si se trata del pensamiento en sí y para sí, podemos seguramente elaborar, como lo hizo Fichte, un "sistema de libertad" en la plena coherencia de una construcción que somete a la ciencia, la moral, la religión y también a la educación. Pero para su semejante (el término ya está viciado si se trata de la libertad del otro) no puede escapar a una cuestión que la limita y fragiliza su acción. ¿Por qué derecho, si la libertad es verdaderamente el fondo de la naturaleza humana, puedo emprender la acción de actuar sobre el otro? ¿No debo, coherentemente, dejar la libertad allí donde ella reside, es decir el otro, así mismo? (2001, pp. 17-18)

En efecto, "la autonomía en su raíz ilustrada como un bien y un objetivo al cual no podemos renunciar sobre todo porque ella es fundamental para el pensamiento y la construcción moral del individuo" (p. 129) le fija unos rasgos a la modernidad pedagógica principalmente porque es la primacía ontológica del sujeto mientras que la heteronomía es un conjunto de principios, obligaciones y responsabilidades hacia el otro (p. 129) e impone un compartir colectivo en los individuos. La vida en comunidad exige el intercambio de ideales, fija un pacto social y promueve el vínculo social necesario para la realización de cada uno. Una educación basada en la heteronomía siempre se ve desde el ángulo de la práctica; una educación anclada en la autonomía es una preparación para la vida en comunidad. Mientras la autonomía traduce el discurso pedagógico escolar moderno, la heteronomía es un discurso social responsable, una práctica de la disposición aprendida en el mundo escolar. La autonomía es un asunto escolar y una práctica de enseñanza; ella es fundadora precisamente de las "pedagogías". Desde lo escolar, posee un doble sentido: genérico-axiológico y operacional-funcional (Barbot \& Camatarri, 1999, p. 8). El primero alude a un valor extendido y aceptado como necesario para los intercambios en el mundo moderno, el segundo es una práctica requerida para saber actuar de acuerdo con los imperativos de la ciencia, la tecnología y las profesiones. La autonomía es una conquista progresiva, nunca definitiva, puesto que debe ser alcanzada en la vida activa. Su rol en los procesos de aprendizaje muestra esta conquista histórica después del siglo XIX; ella parece cumplir el papel de la piedra filosofal pedagógica, el cual podría traducirse en los siguientes términos: sin saber no soy libre, pero ya en el saber mi libertad natural se ve constreñida.

Esta conquista de la autonomía es el resultado de la lucha sostenida por las pedagogías nuevas, el concepto de activo y el lugar que ha alcanzado el niño en el proceso educativo. Así, el discurso pedagógico moderno se matiza por medio de la construcción de dispositivos pedagógicos autonómicos, uno de los cuales es la educabilidad cognitiva. Esta se

... conoce como el conjunto de prácticas, técnicas, instrumentos que tiene por objetivo explícito y principal desarrollar la eficiencia y la autonomización de los aprendizajes reactivando de manera sistemática los procedimientos de pensamiento, estructuras mentales de la persona y sobre la cual ella es consciente [...] (Barbot \& Catamarri, 1999, p. 14)

reconociendo la capacidad de aprender del sujeto. Este debe, sobre todo, tomar conciencia de dicha capacidad para que pueda participar activamente en la sociedad de forma crítica y autónoma. Este principio ha impactado de manera clara los dispositivos de formación y la organización de las pedagogías escolares. Por ejemplo, la corriente de la "pedagogía diferenciada" o de la "diferenciación pedagógica" que en la década de 1970 centró su mirada en el niño como aprendiz, se desarrolló a partir de la explosión 
del modelo homogéneo de los alumnos en el sistema escolar. La autonomía es un aprendizaje individual aunque la presencia del otro sea decisiva.

\section{Autonomía y subjetividad}

Otro concepto clave de la modernidad es la subjetividad, que entendemos como la capacidad de narración del yo. Ella es al sujeto como la esencia es a la materia; traduce la historia del individuo en el mundo, incluso en aquel que nombramos como mágico. El sujeto es a la vez naturaleza y sí-mismo. La subjetividad es la autorreferencialidad del sujeto en un mundo abierto, marcado por el progreso, la modernización y la innovación. La subjetividad existía en el mundo griego como Hypokeimon pero en la modernidad deviene manifestación del yo. Sujeto y subjetividad son en oposición a individuo y actor. Para el discurso moderno, la experiencia del sujeto es singular por su existir individual en el mundo; es plural por los intercambios con otros, porque él es actor de su propia historia. El sujeto es un existir, un "existir de alguna manera" al que se le reconoce como existir. Sujeto es aquel que nombramos por su existir -el Yo es una relación con la historia-; esto fue así gracias a la tradición del tiempo y a la evolución de la palabra (García Calvo, 1997, pp. 141-148). Sujeto es el Yo, el existir a través de la palabra; él es déjà-là en su afectación colectiva. Nos dice Alain Touraine (1994, p. 263) que "la modernidad no es posible sin una idea de racionalidad y mucho menos sin la formación de un sujeto en-el-mundo capaz de sentirse responsable de sí mismo y de la sociedad". La subjetividad supone esta relación entre sociedad y sujeto, entre el yo y el interés para continuar siendo individualidad. Dios ha sido desplazado del centro del individuo debido al poder de la ciencia y de la tecnología sin que la modernidad llegue a deslocalizar esta misteriosa relación. "El sujeto es la voluntad de un individuo para actuar y ser reconocido como actor" (p. 207).

Es cierto, desde mucho tiempo atrás la cuestión del sujeto causa problema, especialmente en el campo de las ciencias duras. Se sabe que la vida humana ha sido estudiada de manera atómica desde el siglo XVIII, pero la idea según la cual es un organismo vivo susceptible de modificación y de interacción con el medio impuso una idea de sujeto modificable. Ella opera al ritmo de los cambios en el medio e introdujo la idea dominante según la cual el hombre es el resultado de sus interacciones sociales. El ser humano llega a ser libre por la razón y es autónomo por su autorregulación. Su autonomía provendría del exterior, a través de saberes y según la idea de autoeco-organización (Morin, 2002). El ser humano como organismo vivo tiene la capacidad autonomizarse, capacidad que incluso una máquina "automática" no puede alcanzar. La interacción entre individuo y sociedad refleja la conciencia de sí, característica fundamental de la autonomía; ella es necesaria para acceder a la conciencia colectiva independientemente de los límites de la norma social y cuya subjetividad depende más de las interacciones entre diferentes mundos donde es capaz de diluirse (Castoriadis, 2002). En consecuencia, la subjetividad es una relación imprecisa; les otorga a los individuos una capacidad de ser-en-el-mundo y al hacerlo ocupa un lugar en lo vocativo; es también lo que se nombra como experiencia individual y colectiva. La educación moderna es fuente de subjetividad por los saberes y el ejercicio de la ciencia, las relaciones sociales, el aprendizaje de valores, la experiencia frente a las formas de poder y una espiritualidad. El individuo moderno deviene sujeto gracias a lo que aprende y por el despliegue de su conciencia en el mundo. La conquista de otros mundos de la vida (moral, ciencia, arte o política) y la relación con los otros incide en la formación de su conciencia. Sujeto es, a la vez, historia e interacciones de un individuo; es un sí mismo escindido. El individuo también es nombrado sujeto según la experiencia vivida en el saber (Charlot, 1997, pp. 35-55). Pensar el sujeto desde el punto de vista de su autonomía y subjetividad es un asunto de modernidad. En efecto, ella se define en el campo educativo por la separación entre individuo y sociedad; porque la sociedad a la que han de pertenecer los jóvenes es cada vez más una sociedad de técnicas y de intercambios y cada vez menos una sociedad de orden, símbolos y jerarquías (Touraine, 1995 p. 139).

\section{Conclusión}

La libertad que engendra el discurso ilustrado tiene eco en el discurso pedagógico moderno pues esta ya no sería el momento de acompañamiento moralizador que el esclavo griego ejercía sobre el hijo del amo. Acompañándolo hasta el pórtico del Liceo, el esclavo cuidaba, daba consejos, orientaba al hijo del amo. Tampoco era el disciplinamiento del hermano cristiano. La pedagogía moderna fabricó un tipo de sujeto dócil, introdujo las prácticas de encauzamiento de la conducta y moralizó higienizando el cuerpo del plebeyo. En el primer caso, esta condición se desvanece en la modernidad pedagógica pues el pedagogo deviene una condición de métodos, técnicas, dispositivos. En el segundo caso, a este sujeto se le nombrará preceptor o instructor, sujetos cuya función consistía en moralizar en un espacio definido por el naciente Estado-nación y al que no cesamos de llamar escuela, 
lugar de construcción de la nación. Allí enseñaban las técnicas del leer, contar, escribir, disposiciones y prácticas requeridas en el ideal moderno y en función de la higienización del alma de la plebe. Los oficios requerían de un saber liberador cuya técnica encauzaba la mano, la mente y el cuerpo. El saber es liberador en el espíritu del ideal moderno y esto porque la modernidad se opone, lucha, enfrenta a la superstición, la hechicería y el dogma. El saber liberador no era otro que el poder de la ciencia y fue allí donde se dio inicio al sofisticado conjunto de métodos para enseñar y aprender.

En todo, la pedagogía moderna está organizada sobre la base de la libertad y su realización no tiene otro espacio que el de la escuela. En efecto, la escuela moderna se inspira en la libertad ilustrada ya sea para salvar a los más desheredados de la humanidad, ya sea para forjar en ellos una esperanza que encierra. En cualquier caso, la pedagogía moderna hizo de la libertad su más sofisticado discurso y de allí se desprenden las más sutiles prácticas. Los pedagogos modernos supieron aterrizar este potente discurso e hicieron de él el más fino ejercicio del detalle. El cuerpo, la mente, la mano fueron su más valioso objeto. Además, el poder liberador de la modernidad pedagógica encontró en la autonomía el más preciado aliado. Que los plebeyos aprendan a pensar, contar, escribir; en otras palabras que sean moralizados e higienizados pues en "la oscuridad de la plebe" se anidaba el anti-progreso. Lo moderno es progreso y esto marca de entrada la encrucijada de una forma de libertad y unos métodos de subjetivación. El hombre moderno no puede concebirse por fuera de los límites de su libertad ni de su autonomía, siempre se requiere que sea activo. El ideal moderno se desplaza hacia la pedagogía para hacer de ella el espacio de posibilidad del hombre y de un tipo egocéntrico de educación. El concepto de activo inaugura, así, el poder de un discurso centrado en los aprendizajes, pues aprender es ser moderno, insta al progreso y vaticina un mejor vivir. En síntesis, la pedagogía moderna encierra tres grandes elementos: saber, yo, mundo. Toda relación con el saber es fuente de apertura al mundo y de encuentro con los otros; toda relación con el saber nos conduce al seno de nuestro propio existir. Toda relación con el saber es: relación con el mundo, los otros y con-sigo mismo (Charlot, 1997). Toda relación con el saber es un asunto de libertad y de autonomía; conceptos inspiradores de la pedagogía moderna.

Así mismo, todo saber es fuente de subjetividad y esta es un mecanismo sofisticado de fabricación de lo humano, de un cuerpo siempre dispuesto a funcionar, disciplinado, higienizado. Tal subjetividad se vuelve práctica en el hacer, aprendiendo, enseñando. Solo en el aprendizaje organizado, orientado, provisto de objetividad, de objetivo, el ser humano encauza su condición y se reafirma en el proyecto liberador. Esta condición, ilustrada, se desplaza con el tiempo y se anida en el espíritu más noble del pedagogo moderno. Igualmente, ella es inherente a la autonomía lo que va a traducirse en la modernidad pedagógica como saberes organizados y escolarizados. Así, por ejemplo, Meirieu ilustra esta idea en su pensamiento:

Porque, "aprender su autonomía” es, sin duda, desprenderse de los otros -en el sentido de escapar a su poder- pero también es brindarles a los otros la posibilidad de escapar a mi propio poder; darles la posibilidad de aprender, de oponerse, de resistir o de adherirse a mi proyecto [...] en este sentido, la autonomía es una conquista colectiva que puede tener lugar, entre muchas cosas, por la puesta en práctica de dispositivos de metacognición en el cual emergen y se reconocen los sujetos como diferentes. La autonomía es una finalidad pedagógica en tanto que ella es una promoción colectiva e interactiva de sujetos libres quienes se otorgan el poder de decir recíprocamente "Yo". (1991, p. 149)

La modernidad pedagógica, aquella que reconocemos en diferentes discursos, prácticas, dispositivos apuntó a la fabricación del sujeto disciplinado y al hacerlo introdujo un sistema de verdad al punto que todo aquello que esté por fuera de la escuela no tiene el crédito de saber ni de poder. La educación escolar libera por la autonomía de la razón, por el progreso del saber, por la fiabilidad del juicio y al hacerlo introdujo, fabricó, moldeó un tipo de ser humano incapaz de pensarse a sí mismo y por fuera de tal racionalidad. En este orden de ideas, me pregunto: ¿Podremos seguir hablando de modernidad en un mundo de medidas y límites incluso en la ciencia? ¿Es posible hoy continuar creyendo en la existencia de un sujeto autónomo y en el poder liberador de la ciencia, cuando el individuo se encuentra más que nunca en esta individualidad que impone el miedo colectivo de un mundo sin referencias? En esta perspectiva, Zygmunt Bauman nos muestra que la imposibilidad autonómica se debe al hecho de que vivimos en la sociedad del miedo, donde los individuos viven replegados sobre sí mismos. Vivimos más en una sociedad líquida, siempre en una especie de fuga donde las referencias son de otro orden: seguridad en los espacios públicos, ambivalencias en la relaciones con los otros, repliegue sobre nosotros mismos, intercambios por medio de un sistema virtual sofisticado, etc. (Bauman, p. 2005). Tal vez, la pedagogía moderna haya sido el dispositivo más feroz de construcción del 
hombre máquina; un sujeto capaz de vivir a diferentes velocidades pero sin la capacidad de reducirlas para contemplar el mundo de otro modo.

\section{Referencias bibliográficas}

Avanzini, G. (1998). Les invariants philosophiques de l'acte pédagogique. En Le pédagogue et la modernité, sous la direction de Soëtard Michel et Christian Jamet, Actes du colloque d'Angers, 9-11 juillet, 1996, Neuchâtel, Suisse, Peter Lang.

Barbot, M. J. \& Camatarri, G. (1999). Autonomie et apprentissage: Innovation dans la formation. París: PUF.

Bauman, Z. (2005). Modernidad y ambivalencia. Barcelona. Anthropos.

Best, F. (1996). Comment apprendre: les apports de l'éducation nouvelle. En Les chemins de l'apprentissage. París: Retz.

Castoriadis, C. (2002). Sujet et vérité dans le monde socialhistorique. París : Editions du Seuil, Séminaire du 18 mars 1987.

Charlot, B. (1997). Du rapport au savoir: Éléments pour une théorie. París : Anthropos.

Gadamer, H. G. (1997). Mito y razón. Barcelona: Paidós.

García Calvo, A. (1997). Sobre el sujeto. En Las identidades del sujeto. Valencia: Pre-textos.

Houssaye, J. (1992). Les valeurs à l'école. París: PUF.
Jameson, F. (2004). Una modernidad singular. Ensayo sobre la ontología del presente. Barcelona : Gedisa.

Kant, E. (1983). Fundamentación de la metafísica de las costumbres. Madrid: Espasa Calpe.

Kant, E. (2006). Filosofía de la historia. 11. ${ }^{\text {a }}$ ed. México: FCE.

Korczak, J. (1979). Comment aimer un enfant. París : Robert Laffont.

Meirieu, P. (1991). Le choix d'éduquer: Éthique et pédagogie. París: ESF.

Meirieu, P. (1998). "Le pédagogue et les défis de la modernité". En Le pédagogue et la modernité. Actes du Colloque d'Angers 9-11 juillet 1996, sous la direction de Michel Soëtard et Christina Jamet, Neuchâtel, Suisse, Peter Lang.

Morin, E. (2002). La noción de sujeto. En Nuevos paradigmas, cultura y subjetividad. Buenos Aires: Paidós.

Philonenko, A. (1999). La liberté humaine dans la philosophie de Fichte. 3 ed. París: Vrin.

Ricoeur, P. (1990). Soi-même comme un autre. París: Editions du Seuil.

Soëtard, M. (2001). Qu'est-ce que la pédagogie? Issy-les Moulineaux: ESF.

Touraine, A. (1994). Critique de la modernité. Paris: Les Éditions Fayard.

Tourain, A. (1995). L'école du sujet. En Les Entretiens Nathan. Actes V, "Savoirs et savoir-faire", Nathan Pédagogie, pp. 135-153. 
